\title{
Role for cyclin D1 in UVC-induced and p53-mediated apoptosis
}

\author{
Hirofumi Hiyama ${ }^{1}$ and Steven A. Reeves ${ }^{*, 1}$ \\ 1 Molecular Neuro-Oncology, Neuroscience Center, Neurosurgical Services, \\ Massachusetts General Hospital and Harvard Medical School, Boston, \\ Massachusetts 02129, USA \\ * corresponding author: Steven A. Reeves, Molecular Neuro-Oncology, \\ Neuroscience Center, Massachusetts General Hospital, 149 13th Street, \\ Charlestown, MA 02129, USA. tel.: (617) 726-5510; fax: (617) 726-5079; \\ e-mail: reeves@helix.mgh.harvard.edu
}

Received 13.10.98; revised 19.03.99; accepted 23.03.99 Edited by T. Cotter

\begin{abstract}
DNA damaging agents such as ultraviolet (UV) induce cell cycle arrest followed by apoptosis in cells where irreparable damage has occurred. Here we show that during early phase G1 arrest which occurs in UV-irradiated human U343 glioblastoma cells, there are (1) decreases in cyclin D1 and cdk4 levels which parallel a loss of S-phase promoting cyclin D1/cdk4 complexes, and (2) increases in p53 and p21 protein levels. We also show that the late phase UV-induced apoptosis of U343 cells occurs after cell cycle re-entry and parallels the reappearance of cyclin D1 and cdk4 and cyclin D1/cdk4 complexes. These findings suggest that cyclin D1 can abrogate UV-induced G1 arrest and that the p53-mediated apoptosis that occurs in these cells is dependent on cyclin D1 levels. We examined these possibilities using U 343 cells that ectopically express cyclin D1 and found that indeed cyclin D1 can overcome the cell cycle arrest caused by UV. Moreover, the appearance of $\mathrm{p} 53$ protein and the induction of apoptosis in UV-irradiated cells was found to be dependent on the level of ectopically expressed cyclin D1. These findings, therefore, indicate that expression of cyclin D1 following DNA damage is essential for cell cycle re-entry and p53-mediated apoptosis.
\end{abstract}

Keywords: cyclin D1; UVC; p53; apoptosis; cell cycle

Abbreviations: UV, ultraviolet; IR, ionization radiation; cdk, cyclindependent kinase; pRB, retinoblastoma gene product; PBS, phosphate buffered saline; SDS-PAGE, sodium dodecyl sulfatepolyacrylamide gel electrophoresis

\section{Introduction}

DNA-damaging agents, such as UV or ionization radiation (IR), induce expression of the p53 tumor suppressor gene. ${ }^{1} \mathrm{~A}$ large body of evidence has accumulated implicating wild type p53 protein as having a central role in cell cycle arrest and induction of apoptosis. ${ }^{2}$ The G1 cell cycle arrest elicited by $\gamma$ - irradiation of human fibroblasts is mediated by the p53induced cyclin/cdk inhibitor, p21. ${ }^{3}$ Cell cycle progression through the G1/S boundary is controlled by G1 cyclins, including $D$ and $E$ type cyclins and their cyclin-dependent kinases (cdk), whose phosphorylation of the retinoblastoma gene product ( $\mathrm{pRB}$ ) causes a dissociation of the pRB and $\mathrm{E} 2 \mathrm{~F}-1$ interaction, and subsequent activation of E2Fmediated transcription. As an universal inhibitor of cdks, p21 can inhibit phosphorylation of pRB and allow for G1 arrest. ${ }^{4}$

Recent studies have shown that overexpression of cyclin D1 in serum-starved cell types can induce apoptosis. ${ }^{5}$ Interestingly, the induction of the cell death program was found to be associated with an increase in cyclin D1dependent kinase activity. ${ }^{6}$ Moreover, in cells that contain wild-type p53, the overexpression of E2F-1 leads to Sphase entry and p53-dependent apoptosis. ${ }^{7}$ In a similar fashion, ionizing radiation increases the expression of E2F1 and the entry of cells into S-phase, leading to the process of apoptosis. ${ }^{8}$ These results suggest that deregulation of the $\mathrm{pRB} / \mathrm{E} 2 \mathrm{~F}$ pathway is a key event in some types of apoptosis.

In this report, we demonstrate that (1) UV treatment of U343 glioblastoma cells leads to an induction in cyclin D1 protein levels which promotes S-phase entry and p53mediated apoptosis; and (2) the level of cyclin D1 influences the time of appearance of p53 protein and therefore the apoptosis caused by UV, suggesting a cyclin D1-mediated mechanism for regulation of p53 levels.

\section{Results}

Initially, the cellular response to UV light of human glioblastoma U343 cells was examined by irradiation of the cells with $150 \mathrm{~J} / \mathrm{m}^{2}$ of UVC light. Viability of the irradiated cultures over time, as determined using the trypan blue exclusion method, was unchanged compared with control cultures 24 and $48 \mathrm{~h}$ after treatment (Figure 1A); however, after $72 \mathrm{~h}$, viability of the treated cultures decreased by at least $35 \%$ and remained at this level for up to $120 \mathrm{~h}$ following treatment (Figure 1A).

The remarkable shift in cell viability $72 \mathrm{~h}$ after UVirradiation prompted us to examine the levels of the cell cycle regulatory proteins cyclin D1, cdk4, p53 and p21 after treatment. Interestingly, at early time points after UVirradiation, between $6-24 \mathrm{~h}$, cyclin D1 levels were decreased (approximately $1 / 4$ of the levels in control cells); however, at later time points, between $36-72 \mathrm{~h}$, cyclin D1 levels had rebounded and were in fact increased twofold of the levels in control cells) (Figure 1B). Similarly, UVirradiation caused an initial decrease in cdk4 levels, between $12-36 \mathrm{~h}$, but at later time points, between 48 $72 \mathrm{~h}$, resulted in an increase (Figure 1B). The reduction of cyclin D1 and cdk4 at early times may be due to the degradation effect of UV light. ${ }^{9,10}$ Consistent with the 
Western blotting results, coimmunoprecipitation experiments using cdk4 antibody indicated that S-phase promoting cyclin D1/cdk4 complexes were undetectable 2-36 $\mathrm{h}$ following UV-irradiation; however, cyclin D1/cdk4 complexes were again detectable between 48-72 h after treatment. These results are compatible with an initial and transient UV-induced cell cycle arrest (between 6-24 h) followed by a later re-entry into the cell cycle (between $36-$ $72 \mathrm{~h}$ ). In agreement with the UV-induction of an early

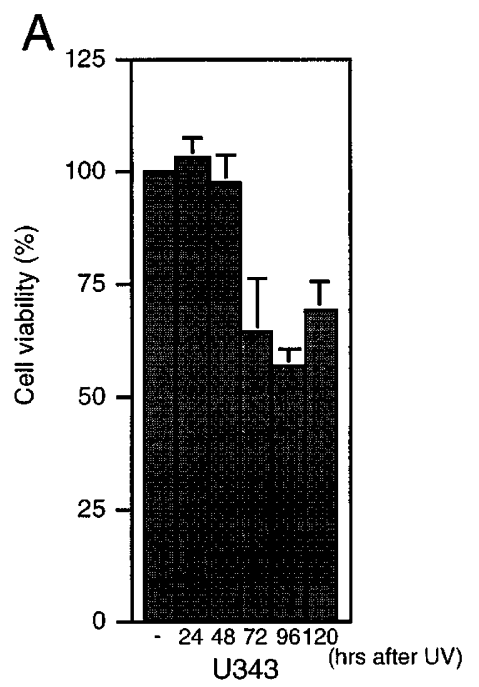

B

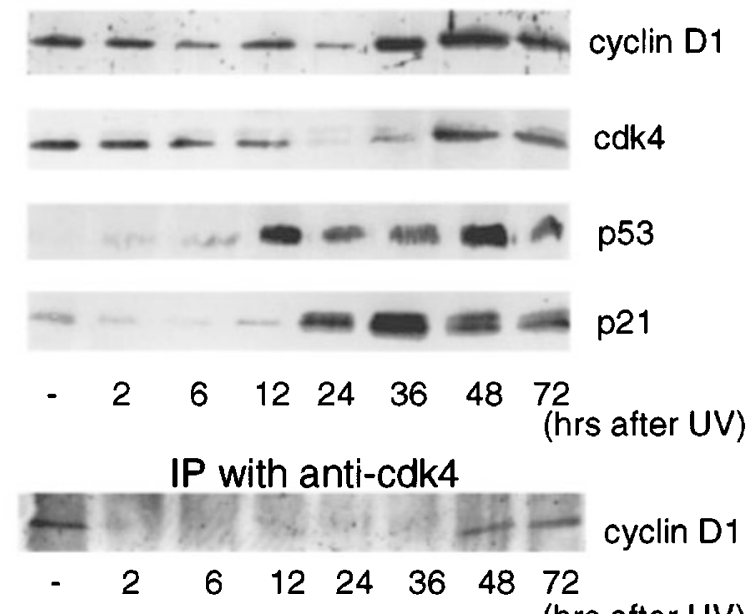

\section{U343}

Figure 1 Cell viability (A), Western blotting and immunoprecipitation (B) of UV-irradiated U343 cells. Asynchronously growing U343 cells were irradiated with UVC light and grown in growth media and then harvested at the indicated times. Non-irradiated U343 cells were used as a control (-). (A) cell viability and cell numbers were determined using the trypan blue inclusion method. All time points were done in triplicate and standard deviations are indicated. (B) cells were lysed in boiling SDS-containing sample buffer and equal amount of lysate were analyzed by Western blotting and probed with antibodies to the indicated proteins. For immunoprecipitation, cells were lysed in nondenaturing sample buffer and equal amount of lysates were immunoprecipitated with anti-cdk4 antibody and blotted with antibody against cyclin D1 phase cell cycle arrest, increased levels of p53 protein were detectable at $12 \mathrm{~h}$ (approximately eightfold of the levels in control cells), followed by an increase in the levels of the p53-inducible cdk inhibitor p21 protein. Interestingly, levels of p53 protein declined between $24-36 \mathrm{~h}$ following UV-irradiation ( $1 / 2$ the level observed at $12 \mathrm{~h}$ ), but then were again detectable at $48 \mathrm{~h}$ (1.5-fold the level observed at $12 \mathrm{~h}$ ). p21 levels peaked at $36 \mathrm{~h}$ following UV-treatment, but was still clearly induced after $72 \mathrm{~h}$.

We next performed flow cytometry on UV-irradiated cells to assess and compare the cell cycle phase with the induction of cell death (Table 1). Initially, UV-irradiation of U343 cells resulted in an accumulation of cells in the G0/ G1 phase that peaked between 24-36 h; however, between 36-48 $\mathrm{h}$ there was a dramatic increase in G0/ G1 phase cells and an increase in S-phase cells. The latter results indicate that the effect of UV-irradiation on U343 cells at later time points is to release the cells from $\mathrm{G} 1$ arrest. Interestingly, this UV-induced redistribution of cells from G0/G1 to S-phase corresponds to the period when cyclin D1 and cdk4 are induced $(36-48 \mathrm{~h}$, respectively; Figure 1B). As expected from Figure 1A, viability of UVirradiated U343 cultures decreased by approximately one third $72 \mathrm{~h}$ after treatment. Importantly, the shift from G0/G1to S-phase and decreased cell viability were associated with the reappearance of cyclin D1/cdk4 complexes (Figure 1B). In agreement with these findings, we have observed similar results in UV-irradiated NIH3T3 cells (data not shown). These findings are also in agreement with previous studies showing that overexpression of cyclin D1 can induce apoptosis by either increasing cyclin D1/cdk4 activity $^{6}$ or significantly increasing the fraction of hyperphosphorylated pRB. ${ }^{5}$

To define more precisely the role of cyclin D1 during UVinduced cell cycle arrest and induction of apoptosis, we used U343 cells that ectopically express cyclin D1 in a tetracycline-dependent fashion (U343-D1 cells). ${ }^{11}$ We have shown previously that ectopic expression of cyclin D1 in U343-D1 cells is detectable $12 \mathrm{~h}$ after removal of tetracycline. ${ }^{11}$ We also observed in these experiments a 2-3-fold increase in p53 expression between 36 and $48 \mathrm{~h}$ after removal of tetracycline. To achieve maximal levels of ectopically expressed cyclin D1 prior to UV-irradiation of U343-D1 cells, tetracycline was removed from cultures $24 \mathrm{~h}$ prior to irradiation. In contrast to the effect of UV on parental U343 cells where decreased cell viability was not

Table 1 Cell cycle distribution of UV-treated U343 cells ${ }^{\mathrm{a}}$

\begin{tabular}{lrrrrrr}
\hline Per cent $^{\text {b }}$ & \multicolumn{1}{c}{${ }^{\mathbf{c}}$} & $\mathbf{1 2}$ & $\mathbf{2 4}$ & \multicolumn{1}{c}{$\mathbf{3 6}$} & \multicolumn{1}{c}{$\mathbf{4 8}$} & $\mathbf{7 2}$ \\
\hline G0/G1 & 69.3 & 70.7 & 77.4 & 73.5 & 58.2 & 42.5 \\
S & 17.9 & 16.5 & 11.8 & 14.1 & 23.5 & 12.3 \\
G2/M & 12.3 & 12.2 & 10.0 & 11.5 & 12.6 & 10.2 \\
Apoptosis & 0.5 & 0.6 & 0.8 & 0.9 & 5.7 & 35.0 \\
\hline
\end{tabular}

aUV-treated U343 cells were harvested at the indicated times and analyzed for DNA content by propidium iodine staining. ${ }^{\text {b}}$ The values indicate the percentage of cells in the G0/G1, S, G2/M phases and apoptotic fraction, and represent the mean value of two separate experiments. "Non-irradiated U343 cells were used as a control 
Table 2 Cell cycle distribution of UV-treated U343-D1 cells ${ }^{\mathrm{a}}$

\begin{tabular}{lrrrrrr}
\hline Per cent $^{\mathrm{b}}$ & $-^{\mathrm{c}}$ & $\mathbf{1 2}$ & $\mathbf{2 4}$ & $\mathbf{3 6}$ & $\mathbf{4 8}$ & $\mathbf{7 2}$ \\
\hline G0/G1 & 68.4 & 69.6 & 70.7 & 69.2 & 44.3 & 25.7 \\
S & 17.3 & 15.6 & 15.4 & 15.3 & 27.4 & 14.9 \\
G2/M & 12.7 & 11.5 & 12.0 & 12.3 & 7.0 & 7.7 \\
Apoptosis & 1.5 & 3.2 & 2.2 & 3.3 & 21.3 & 51.7 \\
\hline
\end{tabular}

aU343-D1 cell were irradiated with UV $24 \mathrm{~h}$ after removal of tetracycline. Cells were harvested at the indicated times and analyzed for DNA content by prodidium iodide staining. ${ }^{\mathrm{b}}$ The values indicate the percentage of cells in the G0/G1, S, G2/M phases and apoptotic fraction, and represent the mean value of two separate experiments.

'Non-irradiated U343-D1 cells were used as a control

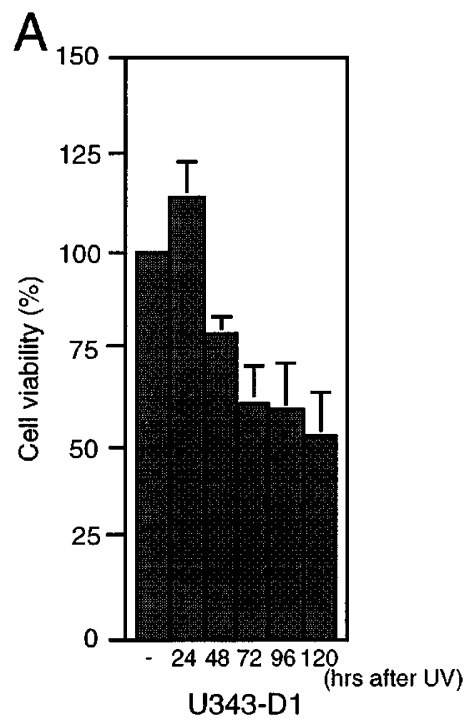

B

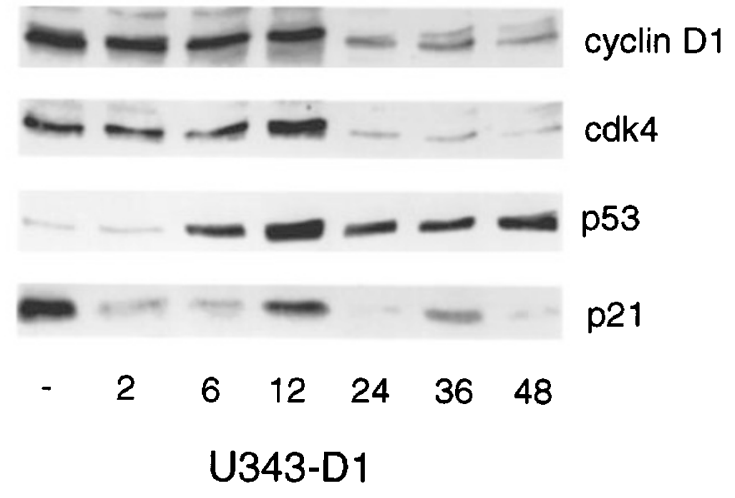

Figure 2 Cell viability (A) and Western blotting (B) of UV-irradiated U343-D1 cells. Asynchronously growing U343-D1 cells grown in the presence of tetracycline were washed with PBS and then growth media lacking tetracycline was added. Twenty-four $h$ later cells were irradiated with UVC light, refed with complete media containing $10 \%$ FCS and harvested at the indicated times. Non-irradiated U343-D1 cells, which were incubated for $24 \mathrm{~h}$ in the absence of tetracycline, were used as a control (-). (A) cell viability and cell number were determined as in Figure 1. All time points were done in triplicate and standard deviations are indicated. (B) cells were lysed in boiling SDS-containing sample buffer and equal amount of lysate were analyzed by Western blotting and probed with antibodies to the indicated proteins observed until $72 \mathrm{~h}$ after treatment, a substantial decrease in cell viability was observed in U343-D1 cultures after only $48 \mathrm{~h}$ of UV-treatment (Figure $2 \mathrm{~A}$ ). Western blotting analysis demonstrated the presence of ectopically expressed cyclin D1 up until $12 \mathrm{~h}$ following treatment, but dramatically reduced levels thereafter (Figure 2B). One explanation for this dramatic decrease is that U343-D1 cells $24-48 \mathrm{~h}$ after UVC irradiation are more easily detached from the plates by the manipulation of washing. Because of this, the decreased level of cyclin D1 during this period very likely represents a population of cells that are resistant to UVinduced apoptosis and are unable to ectopically express cyclin D1. Elevated levels of endogenous cdk4 were also present during the $12 \mathrm{~h}$ following UV-treatment, but were also reduced thereafter (Figure 2B). Compared with parent U343 cells, the increase in p53 protein in U343-D1 cells (greater than fivefold of the levels in control cells) was detectable at an earlier time point ( $6 \mathrm{~h}$ after UV-irradiation of U343-D1 cells and $30 \mathrm{~h}$ after removal of tetracycline in U343-D1 cells). The elevated level of p21 protein in U343D1 cells not exposed to UV-irradiation (Figure 2B, $(-)$ ), is consistent with our previous studies demonstrating endogenous p21 levels increase in parallel with ectopic expression of cyclin D1 in U343-D1 cells. ${ }^{11}$ With UVirradiation, however, p21 levels decreased between 2-6 h, but then reappeared between $12-36 \mathrm{~h}$, presumably through p53-dependent transcriptional activation. Flow cytometry of the irradiated U343-D1 cells indicated an absence of the UV-induced transient G1 arrest observed in U343 cells (compare Table 2 with Table 1); however, the onset of apoptosis in U343-D1 cells was more striking at $48-72 \mathrm{~h}$ after UV-irradiation than in similarly irradiated U343 cells (compare Table 2 with Table 1). Even though cyclin D1 levels are dramatically reduced in U343-D1 cells $24 \mathrm{~h}$ after UV-irradiation (Figure 2B), the cells still re-enter the cell cycle after $48 \mathrm{~h}$ (Table 2). As mentioned above, U343-D1 cells 24-48 h after UV-irradiation were more easily detached from the plates by the manipulation of washing. Thus, the low levels of cyclin D1 detectable during these times is likely coming from a small population of U343-D1 cells that have gained resistance to the UVmediated apoptosis.

\section{Discussion}

The present study demonstrates that UV-irradiation of U343 cells leads to an early G1 arrest that is overcome by a UVdependent increase in endogenous cyclin D1 protein. In agreement with this finding, experiments using U343-D1 cells demonstrated that the UV-induced $\mathrm{G} 1$ arrest can be bypassed by ectopic cyclin D1 expression. Additional support for these findings are studies demonstrating that ectopic expression of cyclin D1 can overcome the G1 arrest caused by serum starvation or ionizing radiation. $5,12,13$

Several studies have linked cyclin D1 expression and the induction of apoptosis: (1) Overexpression of cyclin D1 in specific tumor cell lines results in enhanced apoptosis by selective agents; ${ }^{14}$ (2) Overexpression of cyclin D1 in serum-starved rat fibroblasts can induce apoptosis. ${ }^{5}$ In cultured neuronal cells, the induction of apoptosis by serum 
withdrawal is associated with an increase in cyclin D1dependent kinase activity. ${ }^{6}$ In agreement with these findings, our results with UV-irradiated U343 cells demonstrate that the reappearance of cyclin D1 is associated with induction of apoptosis and that ectopic expression of cyclin D1 in these cells results in an earlier onset of apoptosis.

The ability of UV light to promote S-phase re-entry followed by apoptosis is similar to that of ionizing radiation which by inducing expression of the transcriptional factor E2F-1 increases S-phase entry of cells, leading to apoptosis. $^{8}$ Taken together with our UV results, these findings suggest that the activation of key regulators which accelerate cell progression from $\mathrm{G} 1$ into S-phase are essential in apoptosis caused by DNA-damaging agents.

Our results are in agreement with other studies ${ }^{10,15}$ demonstrating that UV-irradiation of mammalian cells leads to a predictable increase in p53 protein that is responsible for transient G1 arrest and induction of apoptosis. Our findings, however, also indicate that UV light induces an early phase increase in p53 and p21 protein levels that parallels $\mathrm{G} 1$ arrest $^{10}$ and a second late stage increase in p53 levels and decrease in p21 levels that parallels apoptosis. The late stage decrease in the level of p53 protein occurs after the UV-dependent increase in cyclin D1 levels, suggesting cyclin D1 is directly or indirectly responsible for the increase in p53. In support of this, ectopic expression of cyclin D1 in UV-irradiated U343-D1 cells resulted in a significantly earlier appearance of p53 protein than that observed in UV-irradiated U343 cells. Moreover, we have shown previously in U343-D1 cells not exposed to DNA-damaging agents that ectopic expression of cyclin D1 resulted in increased p53 protein level and p53-independent induction of p21 without altering cell cycle progression. ${ }^{11}$ Considering that p53 is a mediator of apoptosis $^{2}$ and that cyclin D1 can induce apoptosis in some cell types, ${ }^{5,6}$ a mechanism whereby cyclin D1 influences p53 levels is likely.

\section{Materials and Methods \\ Cell culture and UVC treatment}

U343 human glioma cells, which are wild-type for the p53 gene, ${ }^{11}$ were grown in DMEM containing $10 \%$ fetal calf serum and penicillin Gstreptomycin sulfate. We used U343 cell clones in which ectopic expression of cyclin D1 could be regulated with tetracycline (U343D1). ${ }^{11}$ Following aspiration of the growth media and washing with phosphate buffered saline (PBS), cells were irradiated with $256 \mathrm{~nm}$ UVC light (150 J/m²) using a Stratalinker (Stratagene). Irradiated cells were then incubated with growth media for the indicated times.

\section{Cell viability and cell cycle analysis}

Cells grown in monolayer were washed with PBS and trypsinized at the indicated times after UV-irradiation and viable cells were counted by the trypan blue exclusion method. For cell cycle analysis, both attached and detached cells were collected, washed with PBS, fixed in $70 \%$ ethanol, incubated in PBS containing $200 \mu \mathrm{g} \mathrm{ml}^{-1}$ RNase A and stained with $50 \mu \mathrm{g} \mathrm{ml}^{-1}$ of propidium iodide. Cell cycle phase analysis was performed using a FACScan (Becton-Dickinson) according to the manufacturer's procedure.

\section{Western blotting}

Western blot analysis was performed as described previously. ${ }^{11}$ Cells grown in monolayer were washed with PBS, harvested and lysed in boiling SDS-containing sample buffer. Equal amounts of lysate $(50 \mu \mathrm{g})$ were boiled for $4 \mathrm{~min}$ in SDS-sample buffer and subjected to $12.5 \%$ SDS-PAGE and then transferred to nitrocellulose membranes (BioRad). The membranes were probed with cyclin D1 (Upstate Biotechnology, Inc), cdk4 (Santa Cruz Biotechnology), p53 (Calbiochem) and p21 (Santa Cruz Biotechnology) antibodies.

\section{Immunoprecipitation}

Cells grown in monolayer were washed with PBS, harvested and lysed in buffer containing $50 \mathrm{mM}$ Tris- $\mathrm{HCl}, \mathrm{pH} 7.5,250 \mathrm{mM} \mathrm{NaCl}, 5 \mathrm{mM}$ EDTA, pH 8.0, 0.1\% Nonidet p-40, $5 \mathrm{mM}$ DTT, $10 \mathrm{mM} \mathrm{NaF}, 1 \mathrm{mM}$ PMSF, $1 \mu \mathrm{g} \mathrm{ml}^{-1}$ aprotinin and $1 \mu \mathrm{g} \mathrm{ml}^{-1}$ leupeptin. Equal amount of lysates $(500 \mu \mathrm{g})$ were precleared with normal mouse serum and then immunoprecipitated with cdk4 antibody and Protein G plus agarose (Oncogene Science). Immunoprecipitated samples were separated on $12.5 \%$ SDS - PAGE, transferred to nitrocellulose and probed with cyclin D1 antibody.

\section{Acknowledgements}

We thank John W. Henson and Lloyd M. Alderson for critical reading of the manuscript. This work was supported in part through the Neurosurgical service, MGH. H. Hiyama was partially supported by scholarships from the Japan Brain Foundation and the Dr. Itoe Okamoto International Exchange Fund.

\section{References}

1. Dulic V, Kaufmann WK, Wilson SJ, Tlsty TD, Lees E, Harper JW, Elledge SJ and Reed SI (1994) P53-dependent inhibition of cyclin dependent kinase activities in human fibroblasts during radiation-induced G1 arrest. Cell 76: 1013-1023

2. Levine AJ (1997) p53, the cellular gatekeeper for growth and division. Cell 88 : $323-331$

3. El-Deiry W et al(1993) WAF1, potential mediator of $\mathrm{p} 53$ tumor suppression. Cell 75: $817-825$

4. Harper JW, Adami GR, Wei N, Keyomarsi K and Ellege SJ (1993) The p21 Cdkinteracting protein $\mathrm{Cip} 1$ is a potent inhibitor of $\mathrm{G} 1$ cyclin-dependent kinases. Cell 75: $805-816$

5. Sofer-Levi Y and Resnitzky D (1996) Apoptosis induced by ectopic expression of cyclin D1 but not cyclin E. Oncogene 13: 2431-2437

6. Kranenburg O, van der Eb AJ and Zantema A (1996) Cyclin D1 is an essential mediator of apoptotic neuronal cell death. EMBO J. 15: 46-54

7. Qin X-Q, Livingston DM, Kaelin Jr WG and Adams PD (1994) Deregulated transcription factor E2F-1 expression leads to S-phase entry and p53-mediated apoptosis. Proc. Natl. Acad. Sci. USA 91: 10918-10922

8. Huang Y, Ishiko T, Nakada S, Utsugisawa T, Kato T and Yuan Z-M (1997) Role for E2F in DNA damage-induced entry of cells into S phase. Cancer Res. 57:3640 3643

9. Pagano M, Theodoras AM, Tam SW and Draetta GF (1994) Cyclin D1-mediated inhibition of repair and replicative DNA synthesis in human fibroblasts. Genes Dev. 8: $1627-1639$

10. Poon RYC, Toyoshima Hand Hunter T (1995) Redistribution of the CDK inhibitor p27 between different cyclin-CDK complexes in the mouse fibroblast cell cycle and in cells arrested with lovastatin or ultraviolet irradiation. Mol. Biol. Cell. 6: $1197-1213$ 
11. Hiyama H, lavarone A, LaBaer J and Reeves SA (1997) Regulated ectopic expression of cyclin D1 induces transcriptional activation of the cdk inhibitor p21 gene without altering cell cycle progression. Oncogene 14: 2533-2542

12. Gadbois DM, Bradbury EM and Lehnert BE (1997) Control of radiation-induced G1 arrest by cell-substratum interactions. Cancer Res. 57: 1151-1156

13. Zwijsen RML, Klompmaker R, Wientjens EBHGM, Kristel PMP, van der Burg B and Michalides RJAM (1996) Cyclin D1 triggers autonomous growth of breast cancer cells by governing cell cycle exit. Mol. Cell. Biol. 16: 2554-2560
14. Han EK, Begemann M, Sgambato A, Soh J, Doki Y, Xing W, Liu W and IB W (1996) Increased expression of cyclin D1 in a murine mammary epithelial cell line induces p27kip1, inhibits growth, and enhances apoptosis. Cell Growth Differ. 7: $699-710$

15. Lu X and Lane DP (1993) Differential induction of transcriptionally active p53 following UV or ionizing radiation: defects in chromosome instability syndrome? Cell 75: $765-778$ 